\title{
НОВЫЕ ТРЕБОВАНИЯ К ОБУЧЕНИЮ РУССКОМУ ОБРАЗЦОВОМУ ПРОИЗНОШЕНИЮ ПОЛЬСКИХ СТУДЕНТОВ-РУСИСТОВ, ИЗУЧАЮЩИХ РУССКИЙ ЯЗЫК С НУЛЕВОГО УРОВНЯ
}

\author{
NEW REQUIREMENTS RELATED TO TEACHING MODEL RUSSIAN \\ PRONUNCIATION TO POLISH STUDENTS OF RUSSIAN LANGUAGE \\ AND LITERATURE WHO ARE AT BEGINNERS' LEVEL
}

\section{ДОРОТА ДЗЕВАНОВСКА}

\begin{abstract}
This article is an attempt to show new ways of teaching model Russian pronunciation to Polish students of Russian language and literature who only begin to learn Russian. The author of the article claims that groups of beginners should not only be taught phonetics during the first several weeks of studies in the form of intensive courses of articulation and intonation. The process of forming correct pronunciation habits in these groups should carefully follow the principle of complexity involved in acquiring speaking skills.
\end{abstract}

Dorota Dziewanowska, Uniwersytet Pedagogiczny im. Komisji Edukacji Narodowej w Krakowie, Kraków - Polska.

Правильное произношение - необходимое условие успешного овладения иностранным языком. Обучение произношению русской речи включает артикуляцию звуков, правильное словесное ударение и интонацию1. Формирование этих трех подвидов произносительных навыков в их взаимосвязи должно являться приоритетной задачей обучения произношению. Однако А.Н. Щукин, исходя их положения, что без произносительных навыков невозможны никакие коммуникативные умения, ставит и другие, не менее важные, задачи: 1) формирование слуховых образцов русских звуков и целых слов на их базе, т.е. навыков опознания (отождествления) слов, словосочетаний и целых высказываний; 2) формирование умений контроля над чужим произношением и самоконтроля; 3) овладение правилами перехода от графического образа слова к его произношению; 4) выработка умения правильно

1 См. Н.А Л ю б и м о в а, Обучение русскому произношению. Артикуляция, постановка и коррекиия русских збуков, Москва 1982, с. 3; см. также: Э.Г А з и м о в, А.Н. Щ у к и н, Словарь методических терминов, Санкт-Петербург 1999, с. 261. 
сочетать звуки в потоке речи; 5) выработка умения правильного членения фраз на синтагмы ${ }^{2}$. Реализация этих задач обеспечивает развитие всех видов речевой деятельности - аудирования, чтения, говорения и письма. Поэтому студенты-филологи должны в максимальной степени усвоить фонетическую норму русского литературного языка. По словам А.Н. Щукина, „это своего рода программа-максимум"з

Отметим, что овладение звуковым строем изучаемого иностранного языка способствует успешности речевого общения. В реальном коммуникативном общении как фонетические, так и другие языковые погрешности являются более заметными, чем ошибки в поведении ${ }^{4}$. Нарушение фонетической корректности речи осложняет общение, так как часто приводит к непониманию сообщаемой информации. Более того, оно нередко вызывает у получателей информации утомление, в результате чего коммуникация может резко прекратиться.

Обучение польских студентов нормам русского литературного произношения имеет свои традиции в Краковском педагогическом университете. Здесь с 1963 года применяется репродуктивно-креативный метод, называемый также текстуально-когнитивным. Автором этого метода является профессор Януш Генцель. Основные теоретические принципы данного метода изложены в монографии Nauczanie języka rosyjskiego metoda reproduktywno-kreatywną ${ }^{5}$ и многих последующих работах Я. Генцеля.

Согласно положениям репродуктивно-креативного метода, занятия в первый год обучения начинаются с интенсивного курса артикуляции, составляющего первый этап обучения и продолжающегося около 6 недель. На первом этапе студенты усваивают знания по фонетике и путем осознанного подражания приобретают артикуляционные навыки. На втором этапе обучения русскому языку репродуктивно-креативным методом проводится интенсивный интонационный курс, который продолжается около 4-х недель. В ходе этого курса студенты теоретически и практически усваивают основные интонационные конструкции, а также знакомятся с правилами синтагматического членения высказывания.

Отметим, что репродуктивно-креативный метод нашел также применение в школьном обучении. С 1973 года этот метод стал приме-

2 См. А.Н. Щ у к и н, Методика преподавания русского языка как иностранного. Для зарубежных фрилологов-русистов, Москва 1990, с. 50.

3 Там же, с. 51.

${ }^{4}$ С.Г. Т е р - М и н а с о в а, Язык и межкультурная коммуникациия, Москва 2000, c. 88 .

${ }^{5}$ J. H e n z e l, Nauczanie języka rosyjskiego metoda reproduktywno-kreatywna, Kraków 1978. 
няться в экспериментальных классах лицеев, а с 1976 года - в экспериментальных классах восьмилетних школ города Кракова и Краковского воеводства. На рубеже 80-х и 90-х годов этот метод стал вызывать все более широкий интерес в среде учителей и применялся в свыше 100 классах восьмилеток на территории 9 воеводств (в основном, на юге Польши)

Дидактические приемы, применяемые при обучении русскому произношению репродуктивно-креативным методом как студентов-филологов, так и школьников, давали положительные результаты. Однако в новой дидактической ситуации, заключающейся в том, что в последнее время на отделение русской филологии стали поступать абитуриенты с нулевым знанием русского языка, приходится решить вопрос, как эту технологию приспособить к изменившимся условиям. В нулевых группах, в которых обучение языку начинается с азбуки, невозможно заниматься фонетикой лишь в течение первых нескольких недель, в ходе отдельных интенсивных курсов артикуляции (1-й этап) и интонации (2-й этап). В данном случае необходимо использовать процедуры, которые применялись в довузовском экспериментальном обучении русскому языку репродуктивно-креативным методом.

В настоящей статье сделана попытка наметить новые пути обучения русскому литературному произношению студентов-русистов, которые начинают изучать русский язык с нулевого уровня.

По моему мнению, в нулевых студенческих группах формирование правильных произносительных навыков должно полностью соответствовать принципу комплексности в обучении видам речевой деятельности. Это обозначает, что с первых занятий 1-го семестра (в ходе вводного алфавитно-фонетического курса) студенты знакомятся с буквами русского алфавита, учатся каллиграфии. При изучении азбуки особое внимание уделяется не только написанию букв, но и звукобуквенным соответствиям. Параллельное формирование каллиграфических и произносительных навыков осуществляется в тесной связи с обучением слушанию, говорению, чтению и письму при одновременном изучении лексико-грамматического и орфографического материала. Поскольку на этом этапе обучения русскому языку студенты учатся читать слоги, слова, словосочетания, предложения и краткие тексты, а также задавать вопросы, отвечать на них, составлять краткие тексты

${ }^{6}$ Zob. D. D z i e w a n o w s k a, J. H e n z e l, Poradnik metodyczny dla nauczycieli do eksperymentalnego podręcznika języka rosyjskiego dla klasy V, Kraków 1986; wyd. II, Warszawa 1988; zob. także: D. D z i e w a n o w s k a, Z doświadczeń nauczania języka rosyjskiego metoda reproduktywno-kreatywna w szkole podstawowej, „Rocznik Naukowo-Dydaktyczny WSP w Krakowie. Prace Rusycystyczne VII", Kraków 1987, z. 116, c. 283-299. 
по изученным темам (в устной или письменной форме), необходимо знакомить их с основными интонационными конструкциями, а также с правилами синтагматического членения высказывания. Учитывая коммуникативную направленность процесса обучения иностранным языкам, последовательность введения букв и фонетического материала необходимо подчинять задачам речевого общения. Однако вводный курс полезно начинать с работы над гласными звуками, так как на материале гласных легко обратить внимание обучаемых на движения органов речевого аппарата7. Итак, в обязательный минимум предлагается включить следующие явления русского литературного произношения: 1) произношение гласных в ударных позициях; 2) существенные изменения гласных в безударных позициях; 3) корреляции согласных по глухости-звонкости и твердости-мягкости; 4) акцентноритмические модели слова; 4) систему интонационных конструкций, их строение и смыслоразличительную роль 8 . В русском языке выделяется семь интонационных конструкций, но студентам-русистам, приступающим к изучению русского языка, достаточно усвоить шесть типов интонационных конструкций (ИК-1, ИК-2, ИК-2а, ИК-3, ИК-4, ИК-5), так как они составляют основу звучащей речи. Отметим, что самая исчерпывающая информация обо всех явлениях русской интонационной системы помещается в работах Е.А. Брызгуновой 9 . Обучение произношению невозможно осуществлять путем простого подражания, поэтому оно должно строиться на когнитивной основе. Этой точки зрения придерживались многие ученые ${ }^{10}$. Ссылаясь на свой преподавательский опыт обучения русскому литературному произношению школьников и студентов, я считаю это положение вполне оправданным. Итак, работу по усвоению звуковой системы русского языка необходимо начинать с изучения определенного фонетического правила. С целью дать студентам возможность осознать различия между

7 См. Т.И. К а п и т о н о в а, Л.В. М о с к о в к и н, Методика обучения русскому языку как иностранному на этапе педвузовской подготовки, Санкт-Петербург 2005, с. 112.

8 См. Н.М. М а л а ш е н к о, Обучение произношению, [в:] Методика преподавания русского языка как иностранного на начальном этапе, Москва 1989, с. 37.

${ }_{9}$ См. Е.А. Б р ы з г у н о в а, Практическая фонетика и интонация русского языка. Пособие для преподавателей, занимающихся с иностранцуами, Москва, 1963.

10 Л.Р. 3 и н д е р, Общзая фонетика, Москва 1979; А.А. Л е о н т ь е в, Н.Д. А н д р е е в а, Методика. Заочный курс повышения квалификации филологов-русистов, Москва 1988; Я. Г е н ц е л ь, Обучение русскому языку как иностранному репродуктивно-креативным методом, „Русский язык за рубежом” 1988, № 2, с. 49-52; Н.А. Л ю б и м о в а, Теоретические основы формирования слухопроизносительных навыков при обучении русскому языку как иностранному, [в:] Русский язык как иностранный и методика его преподавания, Санкт-Петербург 2006, с. 271-280. 
нормами артикуляции родного и изучаемого языков, при обучении русской артикуляции целесообразно использовать знаки фонетической транскрипции. В нулевых студенческих группах преподаватели могут использовать упрощенную фонетическую транскрипцию по системе А. Богуславского и С. Кароляка ${ }^{11}$ или же более сложную транскрипцию по системе А. Мировича ${ }^{12}$. Отметим, что активное овладение фонетической транскрипцией дает студентам возможность лучше осознать особо трудные для них артикуляционные явления, а также способствует прочному закреплению фонетических правил. Процесс формирования произносительных навыков включает несколько фаз:

1) ознакомление с артикуляционным правилом,

2) ознакомление с образцовым произношением данного звука в слове или в нескольких словах с одновременной графической записью этого слова и с использованием транскрипции,

3) имитацию - повторение студентами звукового образца вслед за преподавателем,

4) повторное предъявление образца произношения звука в слове или же в нескольких словах,

5) дифференцировку - осмысление,

6) выполнение студентами артикуляционных упражнений.

Следует обратить внимание на то, что в фазе имитации закрепляются связи слуховых и речедвигательных образцов речевой единицы, формируется способность к воспроизведению, а также развивается слуховой контроль над своим произношением. В фазе дифференцировки происходит осмысление дифференциальных признаков звука (слова, словосочетания), закрепляется способность к воспроизведению13.

По моему мнению, отработку артикуляционного явления следует начинать с предъявления произношения звука в слове или же в нескольких словах. Однако особо трудные для польских студентов звуки полезно отрабатывать в изолированном положении. Этот прием оказывается полезным, например, при артикуляции огубленного $о$ в ударном слоге, переднеязычного $\imath$, звонкого [v] в сочетаниях $c b, m b, k b, u b, x b$. В данном случае преподаватель должен обратить внимание студентов на ощутимые моменты артикуляции. Прием опоры на ощутимые моменты артикуляции является основным приемом так называемого открытого управления. „Ощутимыми называются такие моменты арти-

${ }_{11}$ См. A. B o g u s ł a w s k i, S. K a r o l a k, Gramatyka rosyjska w ujęciu funkcjonalnym, Warszawa 1970.

12 Cм. A. M i r o w i c z, Gramatyka opisowa języka rosyjskiego, cz. 1, Warszawa 1953.

13 См. Е.И. П а с с о в, Основы коммуникативной методики обучения иностранному общению, Москва 1989, с. 164-165. 
куляции, которые поддаются контролю (зрительному, мышечному) и могут выполняться сознательно, т.е. учащийся может произвольно управлять отдельными движениями речевых органов"14. Воспроизвести неощутимые моменты артикуляции помогают специальные приемы скрытого управления артикуляцией. А.А. Леонтьев и Н.Д. Андреева выделяют три группы таких приемов: 1) связанные с благоприятной позицией; 2) связанные с видоизменением оттенка звука; 3) связанные с изменением темпа речи. Открытое и скрытое управление артикуляцией при обучении русскому произношению следует использовать комплексно. Например, при предъявлении артикуляции переднеязычного $\bumpeq$ можно замедлить темп речи (скрытое управление) и одновременно обратить внимание студентов на работу органов речи (открытое управление). Затем приступить к презентации этого звука в ряде слов, пользуясь в данном случае приемом скрытого управления. Предъявление звука $\iota$ в словах целесообразно начинать с так называемой благоприятной позиции и постепенно переходить к неблагоприятным, т.е. трудным, позициям. При выборе благоприятной позиции и последовательном переходе к более трудным позициям стоит руководствоваться особенностями звуковой системы как русского, так и польского языков. Например, польские студенты артикуляцию звука [1] наиболее успешно усваивают в изолированном положении или в конце слова (был, знал, стол, пол), тогда как сочетание ^у в словах ^ук, слушай является для них трудной позицией, поскольку она поддерживает лабиализацию, которую как раз надо снять. Осознать структуру звука помогает также прием утрирования артикуляции, когда звук произносится четко, а движения органов речи выполняются напряженно, с большим усилием. При утрированном произношении звука некоторые неощутимые моменты артикуляции могут стать ощутимыми. Важно, чтобы студенты максимально сосредоточились на работе речевого аппарата. Сначала звук проговаривается про себя, а затем произносится вслух. Этот прием можно сочетать с приемом использования звуков-спутников, основанного на взаимодействии артикуляции соседних звуков в слоге и в слове. Например, для постановки переднеязычного мягкого [р'] можно использовать в качестве звуков-спутников согласные $m, n$ и гласные $u, e: m p u, n p u, n p e$. Для постановки артикуляции трудного для студентов звука можно также использовать и другие приемы, такие как: использование звуков-помощников, использование действия по аналогии ${ }^{15}$. Поставив произношение звука в изолированной

14 А.А. Л е о н т ь е в, Н.Д. А н д р е е в а, Методика. Заочный курс..., указ. соч., с. 61.

15 См. В.С. Д е в я т а й к и н а, В.В. Д о б р о в о льск а я, 3.Н. Ие в л е в а и др., Пособие по методике преподавания русского языка как иностранного для студентов-нефилологоß, Москва 1984; см. также Т.И. К а п и т о н о в а, Л.В. М о с к о в к и н, Методика обучения русскому языку как иностранному на этапе педвузовской подготовки, Санкт- 
позиции и в слогах, непременно надо переходить к работе над произношением слов. При этом преподаватель должен обращать внимание на место ударения в слове, на качество гласных звуков в ударном и безударных слогах, на качество согласных в зависимости от положения в слове, например, оглушение или озвончение согласных.

Описанные выше приемы дают возможность подготовить студентов к сознательному выполнению артикуляционных упражнений. Их можно разделить на три основные группы: 1) постановочные, 2) тренировочные, 3) упражнения на закрепление артикуляционных навыков ${ }^{16}$.

Как упоминалось выше, в ходе вводного курса параллельно с обучением азбуке и артикуляции должна осуществляться работа над интонацией. При ознакомлении студентов с русскими интонационными конструкциями полезно применять следующую последовательность дидактических действий:

1) предъявление правила;

2) звуковое предъявление мелодической линии данной интонационной конструкции (ИК) и демонстрация схемы, иллюстрирующей графическую запись мелодической линии ИК;

3) имитация по образцу предложения вслед за преподавателем;

4) выполнение тренировочных интонационных упражнений;

5) выполнение закрепительных упражнений ${ }^{17}$.

В школьном обучении при постановке интонации оправдались на практике приемы, которые обеспечивают лучшее осознание всех частей данной интонационной конструкции и изменение тона в пределах частей ИК. По моему мнению, самые лучшие результаты (на любом уровне обучения) может дать использование следующих приемов:

- произнесение всех частей интонационной конструкции с разной громкостью: предцентровую часть нормальным голосом, центр - громко, постцентровую часть - очень тихо;

- использование движений рук - преподаватель, произнося предложение, показывает рукой изменение тона, обучаемые повторяют за ним это движение и произносят предложение, сначала про себя, а затем вслух ${ }^{18}$.

-Петербург 2005; см. также: Н.А. Л ю б и м о в а, Теоретические основы формирования..., указ. соч., с. 271-280.

${ }^{16}$ Cм. D. D z i e w a n o w s k a, Ksztattowanie sprawności mownych w procesie nauczania języka rosyjskiego metoda reproduktywno-kreatywna w klasie V $i$ VI szkoły podstawowej, „Prace Monograficzne”, Kraków 1993, nr 175, c. 21.

17 См. Д. Д з е в а н о в с к а, Способы преодоления трудностей при обучении поляков фонетическим нормам русского языка, [в:] Русский язык как иностранный. Теория. Исследования. Практика, Санкт-Петербург 2007, с. 353.

${ }_{18}$ Cм. D. D z i e w a n o w s k a, Kształtowanie sprawności mownych..., указ. соч., c. 55-57. 
Согласно моим наблюдениям, наибольшие трудности у польских студентов вызывает изучение мелодической линии ИК-1. В центре ИК-1 вместо понижения тона студенты повышают тон и усиливают словесное ударение, а постцентровую часть произносят на среднем тоне. Не меньшую трудность доставляет студентам резкое повышение тона в ударной части ИК-3 и произношение заударной части на тоне ниже среднего. Применение ИК-2 также вызывает у студентов трудности. На ударной части ИК-2 студенты очень резко повышают тон, а заударную часть произносят без нужного понижения тона.

Снять трудности, связанные с повышением тона в заударной части ИК-1, ИК-2 и ИК-3, помогает выполнение упражнений с постепенно увеличивающейся постцентровой частью, например:

Он. Он учится.

Он учится в университете.

Где? Где ты был? Где ты был летом?

Ваша ручка? Ваша ручка лежит на столе?

Очень полезными являются упражнения на изменение интонационного центра в предложении. Приведем примеры таких упражнений: Как ваша фрамилия? Как ваша фамилия?; Твою подругу зовут Анна? - Да, Анна. Твою подругу зовут Анна? - Нет, сестру. Твою подругу зовут Анна? - Да, мою. Эти упражнения помогают студентам лучше осмыслить интенцию данного высказывания и тем самым готовят их к реальной языковой коммуникации.

Польские студенты нередко путают интонационные конструкции, поэтому необходимо применять упражнения, построенные по принципу противопоставления, например: ИК-1 и ИК-2а (Это моя ручка. Это моя ручка!); ИК-2 и ИК-2а (Кто это сказал? Кто это сказал!); ИК-1 и ИК-3 (Антон изучает литературу. Антон изучает литературу?). Эти упражнения необходимы также потому, что они помогают готовить студентов к употреблению интонационных конструкций в многосинтагменных предложениях. Следует отметить, что в общении попеременно используются разные типы ИК, поэтому эти упражнения готовят студентов к реальной коммуникации.

Обучение артикуляции и интонации может стать более результативным при условии, что преподаватель будет варьировать технологии обучения в зависимости от задач конкретного занятия и привлекать аутентичные материалы. Приведем несколько примеров упражнений, которые можно успешно использовать для обучения фонетике:

Выделите на слух из сьязного текста слова с тренируемым звуком и запишите их. Определите на слух и запишите последнее слово каждого предложения из прослушанного отрезка речи. 
Прослушайте пары зъуков и поднимите руку, когда услышите новый звук. Прослушайте ряд звуков и поднимите руку, когда услышите заданный збук. Назовите слова, содержащие определенный звук.

Произнесите вслед за диктором звуки (слоги, слова, словосочетания), обращая внимание на произночение указанных звуков.

Произнесите вслед за диктором пары слов, обращая внимание на различне произнотение звуков.

Читайте предложения (текст) в транскрипции.

Повторите по памяти пословииу (скороговорку, стихотворение, текст) сначала медленно, затем в среднем темпе и, наконеи, быстро.

Прослушайте предложения (текст) и определите типы ИК.

Выделите из текста изученную вами ИК.

Выберите в тексте синтагмы, несущие логическое ударение.

Слушайте и определите тип ИК, в зависимости от этого поставьте в конце предложения точку, вопросительный знак или восклицательный знак.

Слушайте текст (диалог), проверьте, правильно ли вы определили интонационно-смысловые центры.

Часть упражнений, приведенных выше, заимствована из Практической методики обучения русскому языку как иностранному 19.

Для повышения привлекательности занятий и мотивации студентов к изучению правильной артикуляции и интонации целесообразно использовать скороговорки, пословицы, стихотворения, отрывки литературных текстов, фонетические игры и конкурсы. При этом на занятиях должен реализоваться принцип зрительной и слуховой наглядности. Зрительные и звукотехнические средства обучения являются эффективным источником повышения качества обучения благодаря яркости и выразительности своих образцов. Повышению мотивационной стороны обучения фонетике особенно способствует применение звукотехнических средств обучения, позволяющих восполнить отсутствие языковой среды на занятиях.

Ссылаясь на мой долголетний опыт работы с польскими студентами над русским образцовым произношением, могу сказать, что образование правильных фонетических навыков обладает следующими преимуществами:

1. Одновременное зрительное и слуховое восприятие слов, входящих в состав фонетических упражнений, облегчает усвоение студентами орфографических норм русского языка.

2. Обучение артикуляции способствует повышению акцентуационной корректности речи студентов и служит базой для дальнейшего обучения русскому словесному ударению с учетом лингвистической информации.

19 Л.С. К р ю ч к о в а, Н.В. М о щ и н с к а я, Практическая методика обучения русскому языку как иностранному, Москва 2011, с. 112-115. 
3. Употребление интонационных конструкций в речи способствует росту мотивации к изучению языка.

Отметим, что у взрослых обучаемых прочно сформированы артикуляционные и интонационные навыки родного языка. В связи с этим им необходимо больше времени для того, чтобы овладеть иноязычными произносительными навыками. Именно поэтому дальнейшее формирование и развитие навыков в области русского литературного произношения должно продолжаться во 2-м семестре, в ходе сопроводительного курса. Проведение сопроводительного курса требует выделения на каждом занятии отдельного компонента, направленного на выполнение так называемой фонетической зарядки, продолжающейся 5-10 минут. Зарядку лучше всего проводить в начальной части занятий, так как она помогает снять фонетические трудности при отработке актуально изучаемого лексико-грамматического материала. Явления, входящие в состав фонетических упражнений, предварительно отбираются преподавателем. Основным критерием такого отбора является пригодность фонетического материала при введении определенной лексической темы, а также при выполнении коммуникативных заданий, осуществляемых на данном занятии. Исходя из положения, что обучение нормам русского литературного произношения должно строиться на когнитивной основе, при выполнении фонетической зарядки целесообразно обращаться к соответствующим фонетическим правилам. Кроме того, при презентации произношения данного слова (слов) следует пользоваться графическими знаками фонетической транскрипции, а выполняя интонационные упражнения - схемами, иллюстрирующими мелодическую линию данной ИК. Формы работы в сопроводительном и вводном курсах совпадают. Однако во 2-м семестре больше места занимает работа с текстом, т.е. слушание текстов, написание диктантов, членение текста на синтагмы и обозначение интонационного центра, чтение вслух. Отработанные в ходе фонетической зарядки слова́ и фразы должны непременно включаться в состав осмысленных коммуникативных высказываний. Во 2-м семестре (так же, как и в 1-м семестре) преобладают упражнения, заключающиеся в репродукции текста. Несмотря на то что при репродукции текста обеспечиваются средства общения, акцент передвигается на смысл фраз. Иначе говоря, репродукция текста непосредственно связана с мыслительной активностью студентов, которые, воспроизводя по памяти готовый (заученный) текст, сосредоточивают внимание на содержании своего высказывания. По-моему, большинство фонетических ошибок, допускаемых студентами при репродукции текста, вытекает из того, что студенты в большей степени думают о том, что сказать, чем о том, как сказать. Репродуцируя текст, студенты убеждены в том, 
что их задача заключается лишь в передаче смысла текста с помощью готовых языковых средств. Наличие этих средств, с одной стороны, дает студентам комфорт высказывания, но, с другой стороны, снижает их готовность следить за правильностью речи. Иначе говоря, у студентов возникает ощущение, что они без изменения, механически произносят заученные слова, предложения, фразы, что освобождает их от необходимости наблюдать за корректностью своего произношения. На этом этапе обучения репродукцию текста постепенно заменяют коммуникативные задания продуктивного характера. Выполняя речевые коммуникативные задания, студенты сосредоточиваются на подборе соответствующих лексико-грамматических средств, на строе предложения или на планировании композиции высказывания и все чаще забывают о необходимости соблюдения норм русского литературного произношения. Поэтому преподаватель должен предугадывать появление типичных ошибок.

В свете сказанного выше важным аспектом работы во вводном и сопроводительном курсах фонетики является исправление ошибок. Постоянное внимание преподавателя к фонетической стороне речи студентов приводит к тому, что студенты сами начинают следить за своим произношением и самостоятельно исправляют свои ошибки. Хорошо, если в случае затруднений они обращаются за помощью к своим коллегам по группе. Формирование самоконтроля, автокоррекции и взаимоконтроля - одно из важнейших умений, особенно по отношению к студентам, которые готовятся к профессии учителя, так как учитель должен не только соблюдать нормы фонетической системы русского языка, но также улавливать на слух ошибки учащихся и быстро реагировать на них.

В заключение следует отметить, что закрепление произносительных навыков студентов должно являться неотъемлемым компонентом занятий по практикуму русского языка на всех последующих этапах обучения. 
